\title{
Electrochemical Characterization of Chromate Free Conversion Coatings on Electrogalvanized Steel
}

\author{
C.R. Tomachuk ${ }^{\mathrm{a} *}$, C.I. Elsner ${ }^{\mathrm{b}}$, A.R. Di Sarli ${ }^{\mathrm{b}}$ \\ ${ }^{a}$ Nuclear and Energy Research Institute - IPEN, National Nuclear Energy Commission - CNEN-SP, \\ Science and Materials Technology Centre - CCTM, Av. Prof. Lineu Prestes, 2242, \\ CEP 05508-000, São Paulo, SP, Brazil \\ ${ }^{\mathrm{b}}$ CIDEPINT: Research and Development Centre in Paint Technology (CIC-CONICET), \\ Av. 52 s/n entre 121 y 122. CP. B1900AYB, La Plata-Argentina
}

Received: November 4, 2012; Revised: September 19, 2013

\begin{abstract}
The chromate conversion treatment is widely used, but it requires highly toxic chromic acid solutions with the consequent effluent disposal and ecological problems. The removal of these toxic chemicals is considered a priority within European Union. The corrosion resistance of three alternative treatments applied on electrogalvanised steel, and immersed in aerated $0.3 \mathrm{M} \mathrm{Na}_{2} \mathrm{SO}_{4}$ solution, $\mathrm{pH} 10$, at $25^{\circ} \mathrm{C}$, was investigated using electrochemical techniques. Their performance was compared with the obtained using the traditional $\mathrm{Cr}^{6+}$-based treatment in the same conditions. The achieved results show that the alternative coatings exhibited discrete protective properties in the sulphate solution. The nitro-cobalt chemical conversion treatment showed similar protective properties than the traditional $\mathrm{Cr}^{6+}$-based treatment, while with the $\mathrm{Cr}^{3+}$-based treatment those were very poor. The phosphate treatment initially performed acceptably but as the time elapsed, its protective properties decreased.
\end{abstract}

Keywords: conversion-coating, electrodeposition, electrochemical techniques, corrosion

\section{Introduction}

Electroplated zinc coating is employed as active galvanic protection for steel. However, zinc is very reactive and thus high corrosion rates of this coating are observed in internal and external atmosphere ${ }^{1}$. For this reason, a post-treatment is necessary to increase their useful life. In current industrial practice, this treatment consists of immersion in a chemical bath that forms a conversion layer over plated zinc. Such a layer behaves as a dielectric passive one with high corrosion resistance, and provides better surface for paint adherence. The main problem of the traditionally used post-treatments is the presence of $\mathrm{Cr}^{6+}$ salts, considered carcinogenic substances whose use is forbidden by European norms ${ }^{2}$. Molybdates, tungstates, permanganates and vanadates, including chromium like elements, were the first chemical elements tried as hexavalent chromium substitutes ${ }^{3-7}$. Recently alternative coatings were also developed based on zirconium and titanium salts ${ }^{8-9}$, cobalt salts $^{10,11}$, organic polymers ${ }^{12,13}$ and rare earth salts ${ }^{14}$. However, the preparation and corrosion behavior of these coatings is not clear and their practical use is doubtful.

In order to find an alternative treatment to $\mathrm{Cr}^{6+}$ conversion coatings, several treatments providing good anti-corrosive behavior, high benefit/cost relation and, mainly, low environmental impact are still to be developed. Usually, the coatings' corrosion performance is evaluated using traditional essays such as Salt Spray ${ }^{15}$, Kesternich tes $^{16}{ }^{16}$, saturated humidity ${ }^{17}$. However, the authors consider important the application of electrochemical methods to obtain faster information about the corrosion reactions kinetics.

*e-mail: tomazuk@gmail.com
Among the electrochemical techniques that can be used, the electrochemical impedance spectroscopy (EIS) was selected based on results already obtained when the bare and/or coated metals corrosion was evaluated ${ }^{18-21}$.

The main purpose of the present work was to find an environmentally friendly conversion treatment that can be used as an acceptable alternative to the $\mathrm{Cr}^{6+}$-based treatment. The corrosion behavior of electrogalvanised steel sheets covered with $\mathrm{Cr}^{6+}$-free treatments was investigated by electrochemical techniques. The obtained results were compared with those coming from applying the traditional $\mathrm{Cr}^{6+}$-based treatment.

\section{Experimental Details}

\subsection{Samples}

Electrogalvanised steel samples $(7.5 \mathrm{~cm} \times 10 \mathrm{~cm}$ $\times 0.1 \mathrm{~cm}$ ) industrially produced and covered with the following conversion treatments: (A) based on $\mathrm{Cr}^{+3}$; (B) nitro-cobalt chemical conversion; (C) phosphate; and (D) traditional $\mathrm{Cr}^{6+}$, were investigated. In each case, a commercial conversion bath was formulated and the coating produced according to the respective supplier recommendations.

\subsection{Thickness measurements}

Coatings thickness was measured using the Helmut Fischer equipment DUALSCOPE MP4. 


\subsection{Morphology}

Coatings morphology was observed by scanning electron microscopy (SEM) and the surface microanalysis was performed by energy dispersive spectrometry (EDXS) using a LEICA $\mathrm{S} 440$ microscopic.

\subsection{Electrochemical behavior}

All measurements were performed at a constant room temperature in aerated 0.3 mol. $\mathrm{L}^{-1} \mathrm{Na}_{2} \mathrm{SO}_{4}$ solution, $\mathrm{pH} 10$, in which the zinc dissolution rate is very slow ${ }^{22}$ at $25 \pm 2{ }^{\circ} \mathrm{C}$. Test electrolytes were prepared from analytical grade materials and distilled water. Solution $\mathrm{pH}$ was adjusted by small additions of $\mathrm{NaOH}$ solution.

The electrochemical cell consisted of a PMMA cylindrical electrolyte holder attached to the coated surface filled with the test solution. The exposed area was $7.07 \mathrm{~cm}^{2}$. The coated metal acted as working electrode, while a $\mathrm{Hg}$ / $\mathrm{HgSO}_{4}(\mathrm{SSE})$ and a platinum mesh were the reference and counter electrodes, respectively. Throughout this paper, all electrochemical potentials are referenced to the Saturated Calomel Electrode (SCE).

Polarization curves were performed with a 1286 Electrochemical Interface at a scan rate of $1 \mathrm{mV} . \mathrm{s}^{-1}$, over the range $-300 \mathrm{mV}<\eta<+200 \mathrm{mV}$ vs. the open-circuit potential. The corrosion current density $\left(\mathrm{i}_{\text {corr }}\right)$ and corrosion potential $\left(\mathrm{E}_{\text {corr }}\right)$ were obtained from the Tafel slopes by extrapolation of the linear portion of the anodic and cathodic branches.

EIS measurements were performed in the frequency range between $10^{-2} \mathrm{~Hz}$ and $10^{5} \mathrm{~Hz}$ using a Solartron 1260 Frequency Response Analyzer coupled to a Solartron 1286 Electrochemical Interface. A sinusoidal signal with amplitude of $13 \mathrm{mV}$ was applied and eight frequency points per decade were registered. The corrosion evolution was analyzed until the appearance of white corrosion products on the samples surface.

All impedance measurements were carried out in a Faraday cage in order to minimize external interference on the system studied.

Taking into account that the corrosion behavior of passivated, painted and/or multi coated materials strictly depends on the production procedure, all the tests were carried out on three replicates of each sample type and the average results obtained for them are reported in the following Tables and Figures.

\section{Results and Discussion}

The thicknesses and compositions of the investigated samples are reported in Table 1. It can be observed that all the samples present similar coating thickness. Samples coated with the treatments $\mathbf{A}, \mathbf{C}$ and $\mathbf{D}$ were lucid grey, while those protected with the $\mathbf{B}$ treatment were dark grey. As it was not possible to obtain information about the passive layer thickness, the values shown in Table 1 correspond to the total coating thickness (zinc plus passive layer).

\subsection{Morphology}

Coatings surface morphology was observed by SEM with magnifications of 2,000X and 10,000X, Figure 1.
Table 1. Thickness and composition of zinc coatings after conversion treatment.

\begin{tabular}{cccc}
\hline $\begin{array}{c}\text { Treatment } \\
\text { identification }\end{array}$ & $\begin{array}{c}\text { Conversion } \\
\text { Treatment } \\
\text { based on }\end{array}$ & Composition & $\begin{array}{c}\text { Coating } \\
\text { thickness } \\
(\mu \mathbf{m})\end{array}$ \\
\hline $\mathrm{A}$ & $\mathrm{Cr}^{3+}$ & $\mathrm{Zn}, \mathrm{Fe}, \mathrm{Cr}, \mathrm{P}, \mathrm{S}$ & $9.1 \pm 0.1$ \\
$\mathrm{~B}$ & nitro-cobalt & $\mathrm{Zn}, \mathrm{Fe}, \mathrm{Co}, \mathrm{P}, \mathrm{S}$ & $9.7 \pm 0.1$ \\
$\mathrm{C}$ & phosphate & $\mathrm{Zn}, \mathrm{Fe}, \mathrm{P}, \mathrm{S}$ & $9.5 \pm 0.1$ \\
$\mathrm{D}$ & $\mathrm{Cr}^{6+}$ & $\mathrm{Zn}, \mathrm{Fe}, \mathrm{Cr}, \mathrm{P}, \mathrm{S}$ & $8.7 \pm 0.2$ \\
\hline
\end{tabular}

In general, the coatings exhibited micro-rough and homogenous structure with irregular size growth.

The surface of the A samples presented a less uniform structure formed by small nodular grains while, at the lower magnification, the B samples exhibited small spherical shaped particles. The surface morphologies of the $\mathbf{C}$ and D samples were very similar and exhibited a plate-like structure, which was more uniform and compact for the latter samples.

Semi-quantitative elemental analysis of surface coatings made by EDXS indicated the presence of S and P; possibly related to the sulfate and phosphate ions contained in the baths compositions. On the other hand, due to the low $\mathrm{Cr}$ content found in the surface, $\mathbf{A}$ and $\mathbf{D}$ samples did not present the network of cracks characterizing the chromate coatings.

\subsection{Electrochemical tests}

Corrosion potential measurements and polarization curves performed on electrogalvanised steel surfaces protected by different conversion treatments but exposed to the same aqueous electrolyte provide an opportunity to better analyze the evolution of their electrochemical behavior. When the overall coating system is considered, it should be noted that, being the thin conversion layer the outermost one, electrochemical interactions between this layer and its environment starts just after getting into contact, particularly if the medium is a saline solution. For that reason, the studied conversion coatings play a paramount role in delaying zinc dissolution, acting as a barrier layer to the diffusion of corrosion inducing species towards the underlying zinc film and/or inhibiting the oxygen reduction reaction by polarizing the cathodic areas.

\subsubsection{Corrosion potential values}

As seen in Figure 2, the corrosion potential $\left(\mathrm{E}_{\text {corr }}\right)$ values of all the coated panels ranged between $-1.02 \mathrm{~V} / \mathrm{SCE}$ and $-1.05 \mathrm{~V} / \mathrm{SCE}$, i.e., at least from the thermodynamic point of view, the chemically different coating layers applied on the zinc surface of those panels did not give rise to marked changes in their electrochemical behavior.

\subsubsection{Polarization curves}

The anodic and cathodic processes of zinc corrosion, dissolution of zinc

$\mathrm{Zn} \rightarrow \mathrm{Zn}^{2+}+2 \mathrm{e}^{-}$

and oxygen reduction 


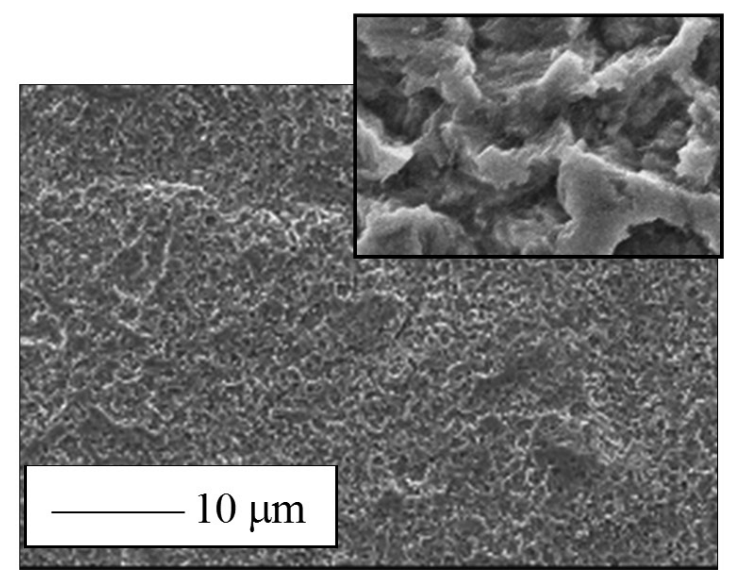

(a) sample protected with treatment $\mathbf{A}$

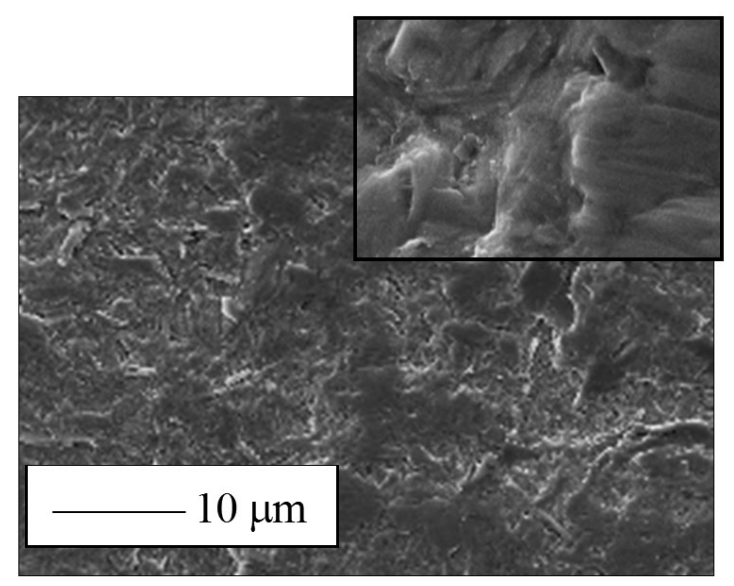

(c) sample protected with treatment $\mathbf{C}$

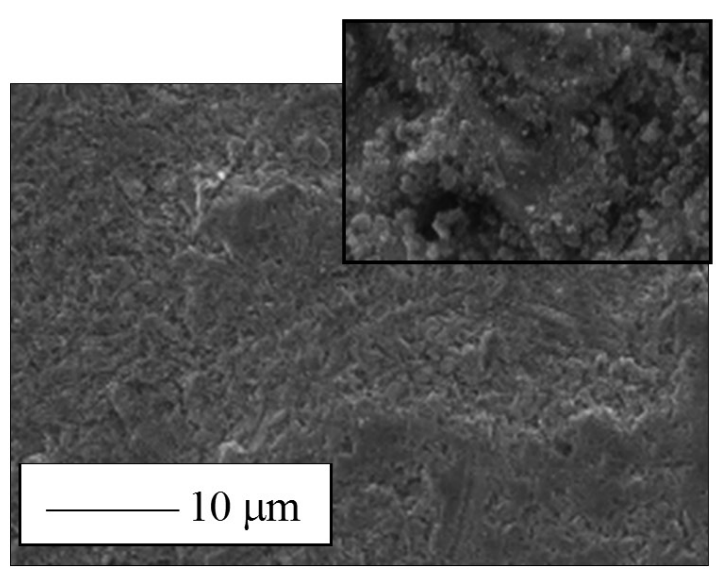

(b) sample protected with treatment $\mathbf{B}$

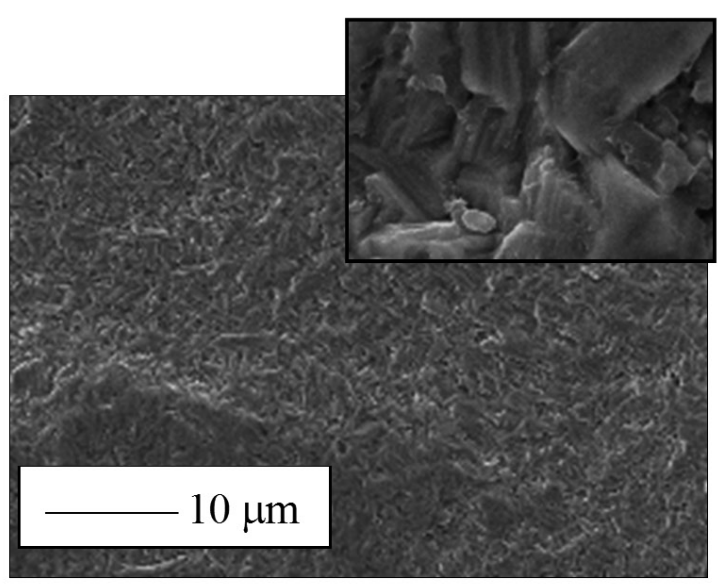

(d) sample protected with treatment $\mathbf{D}$

Figure 1. SEM micrographs of the electrogalvanised steel samples covered with different conversion treatments.

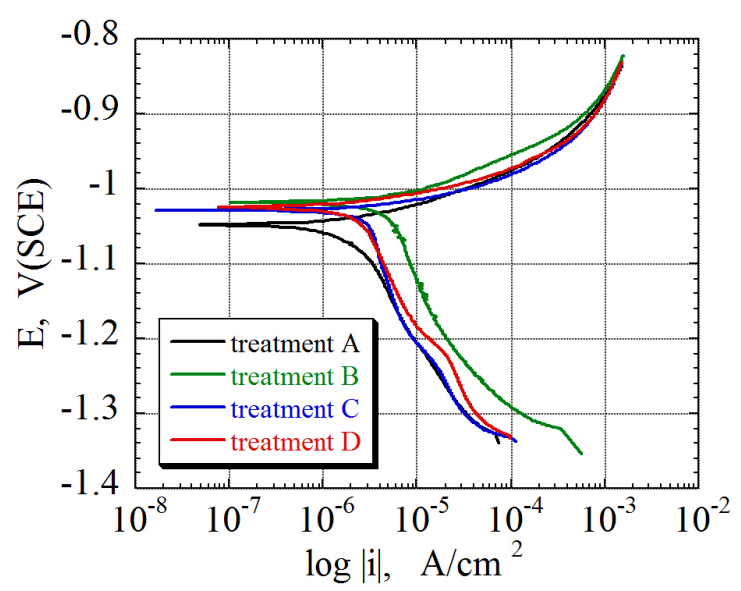

Figure 2. Potentiodynamic polarization curves of electrogalvanised steel protected with the different conversion treatments in aerated $0.3 \mathrm{~mol} . \mathrm{L}^{-1} \mathrm{Na}_{2} \mathrm{SO}_{4}$ solution, $\mathrm{pH}$ 10. Scan rate $1 \mathrm{mV} . \mathrm{s}^{-1}$.
$\mathrm{O}_{2}+2 \mathrm{H}_{2} \mathrm{O}+4 \mathrm{e}^{-} \rightarrow 4 \mathrm{OH}^{-}$

occurred in such a way that the former process took place at defects of the conversion layer and the latter on the surface mostly.

Hence, zinc hydroxide precipitates on the surface and changes to zinc oxide gradually, forming a passive film $^{23}$, as:

$\mathrm{Zn}^{2+}+2 \mathrm{OH}^{-} \rightarrow \mathrm{Zn}(\mathrm{OH})_{2} \rightarrow \mathrm{ZnO}+\mathrm{H}_{2} \mathrm{O}$

Figure 2 depicts typical potentiodynamic polarization curves for electrogalvanised steel samples covered with the different conversion layers and immersed in aerated alkaline sulfate solution. In it can be readily observed that even though the anodic curves did not give much information since the corresponding to the A, C and D samples were rather similar and slightly great than the corresponding to the sample $\mathbf{B}$, after active zinc dissolution, the anodic current density showed a certain trend to reach a limiting value. Such 
a result seems to be due to a diffusion-controlled process derived from the high dissolution rate reached at high anodic overpotentials, which may act as a protective barrier ${ }^{24}$.

The same Figure shows that not only an opposite and slightly more significant difference took place in the cathodic branch, but also that the corrosion rate in the aerated $\mathrm{Na}_{2} \mathrm{SO}_{4}$ medium was under cathodic control (oxygen diffusion) regardless the conversion layer chemical composition. So, the lowest cathodic current density, indicating the more significant suppression of the oxygen reduction reaction, corresponded to the $\mathbf{A}$ and $\mathbf{C}$ samples, followed by the sample $\mathbf{D}$, with a shoulder at $\approx-1.2 \mathrm{~V} / \mathrm{SCE}$ attributed to the onset of the hydrogen evolution reaction. The higher value was shown by the sample B. From the latter results, the polarization level for the oxygen reduction reaction was ranked in the order: treatment $\mathrm{A} \equiv$ treatment $\mathrm{C} \approx$ treatment $\mathrm{D}>$ treatment $\mathrm{B}$.

Table 2 shows that whereas the corrosion potential $\left(\mathrm{E}_{\text {corr }}\right)$ of the electrogalvanised sheet panels covered with the different conversion layers stabilized around $-1 \mathrm{~V} / \mathrm{SCE}$, the corrosion current density $\left(\mathrm{i}_{\text {corr }}\right)$ calculated by extrapolation of the Tafel slopes was also comparable. This feature could be explained in terms of the fact that the porous nature of the studied conversion layers as well as of the corrosion products layer that was being formed allowed, although limitedly, the continuous development of zinc corrosion processes underneath the likely $\mathrm{Zn}$ oxo-hydroxide layer covering the localized conversion layer defects.

\section{EIS Measurements}

\subsection{Impedance spectra}

The assessment of the coatings protective properties was based on the analysis of impedance spectra evolution at different exposure times in the aerated $0.3 \mathrm{~mol} \mathrm{~L}^{-1} \mathrm{Na}_{2} \mathrm{SO}_{4}$ solution.

At first glance, a comparative evaluation of the coatings corrosion resistance was carried out by observing the values of both the $|\mathrm{Z}|$ at low frequencies and the maximum phase angle. The analysis of the phase angle spectra can furnish useful information because it is quite sensitive to coating degradation $^{25}$.

Figure $3 \mathrm{a}$ shows the Bode plots representing the impedance modulus ( $|\mathrm{Z}|)$ vs. frequency for the sample $\mathbf{A}$ at different immersion times in the test solution. As seen, at low frequency $(0.02 \mathrm{~Hz})$ and short immersion times $(<2 \mathrm{~h})$, the $|\mathrm{Z}|$ values increased up to $10^{3} \Omega \mathrm{cm}^{2}$, and after $24 \mathrm{~h}$ of immersion, they were slightly great than this value. The coupled phase angle evolution, Figure $3 b$, allows observing

Table 2. Values of $\mathrm{E}_{\text {corr }}$ and $\mathrm{j}_{\text {corr }}$ of $\mathrm{Zn}$ coatings after conversion treatment.

\begin{tabular}{ccc}
\hline $\begin{array}{c}\text { Treatment } \\
\text { Identification }\end{array}$ & $\begin{array}{c}\mathbf{E}_{\text {corr }} \\
\text { V(SCE) }\end{array}$ & $\begin{array}{c}\mathbf{i}_{\text {corr }} \\
\mu \mathbf{A . c m}^{-2}\end{array}$ \\
\hline A & -1.05 & 3.00 \\
B & -1.02 & 4.00 \\
C & -1.02 & 3.00 \\
D & -1.02 & 3.00 \\
\hline
\end{tabular}

a first time constant with a maximum value of $58^{\circ}$ while, at low frequency $(0.02 \mathrm{~Hz})$, the curves suggest the appearance of a shallow second time constant which remained after $24 \mathrm{~h}$ of immersion. This confirms the presence of the corrosion products that, nevertheless, are not very protective as the impedance modulus slightly decreases. For this immersion time, the high frequency phase angle slightly deformed in comparison with the other situation would be indicating the onset of a new process that accelerates the interfacial reactions. This process could be, for instance, diffusion of aggressive species through the non-protective corrosion products. After $2 \mathrm{~h}$ of immersion, at medium frequencies, a small modification of this time constant took place. A possible explanation for this behavior is based on the assumption that the conversion coating was not compact.

Figure $4 \mathrm{a}$ shows the Bode plot of $|\mathrm{Z}|$ vs. frequency at different immersion times in the test solution for the sample B. It can be seen that except for the diagram acquired just after the immersion, which can represent a very unstable situation, the impedance at low frequency $(0.02 \mathrm{~Hz})$

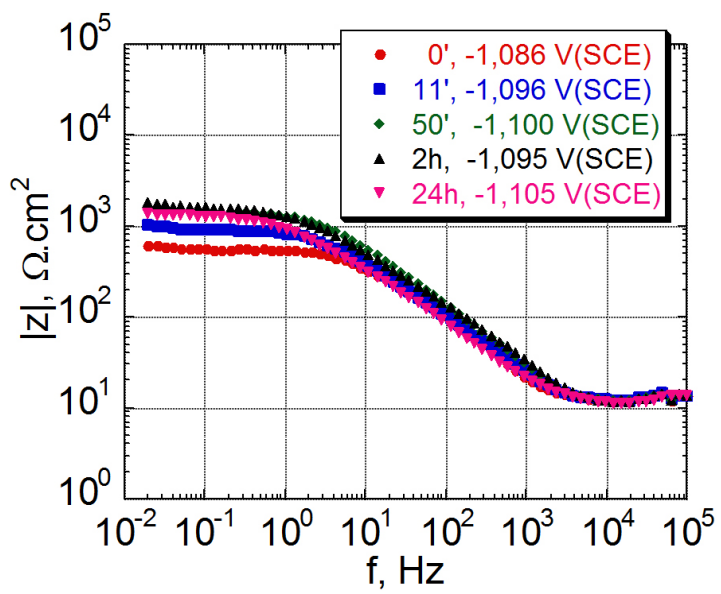

(a)

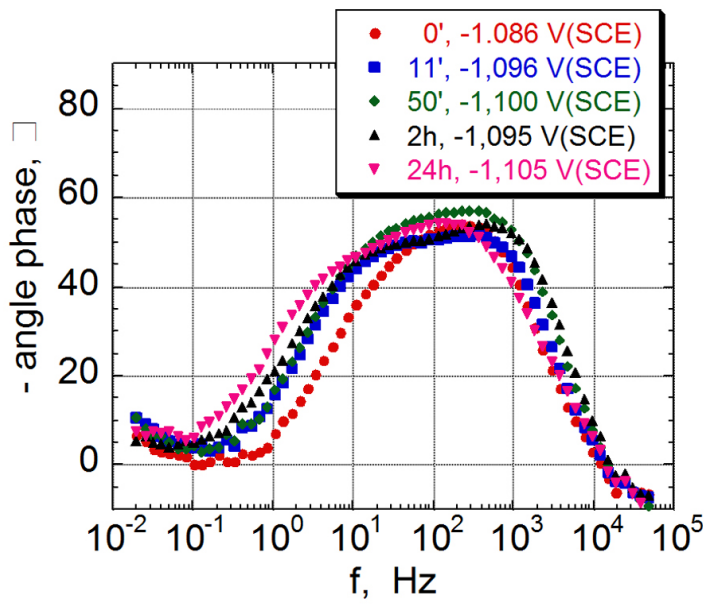

(b)

Figure 3. (a) Bode magnitude and (b) phase angle plots as a function of immersion time in aerated $0.3 \mathrm{~mol} . \mathrm{L}^{-1} \mathrm{Na}_{2} \mathrm{SO}_{4}, \mathrm{pH} 10$, solution for $\mathrm{Cr}^{3+}$ chromated electrogalvanised steel coating - sample protected with treatment $A$. 
increased with the immersion time indicating improvement of the overall protective properties. This improvement was attributed to the sealant effect afforded by the zinc corrosion products gathered within the micropores and/or other coating defects. As well, Figure $4 \mathrm{~b}$ shows that at the beginning of the test a time constant with a maximum phase angle value of $55^{\circ}$ was well defined, and that after $50 \mathrm{~min}$ of exposure a second time constant indicating the onset of the corrosion process was clearly defined. After $24 \mathrm{~h}$, the second time constant merge as the phase angle and it is very wide and deformed. The high frequency time constant is wide and deformed indicating an overlapping of processes. This is valid for all the immersion times, even though for $50 \mathrm{~min}$ and 2 hours the two time constants are clearly separated. In the low frequency region, there are almost no differences between the phase angle responses for the experiments after $11 \mathrm{~min}$.

Figure 5a shows the $|\mathrm{Z}|$ vs. frequency at different immersion times in the test solution for the sample C. As seen, except for the diagram acquired just after

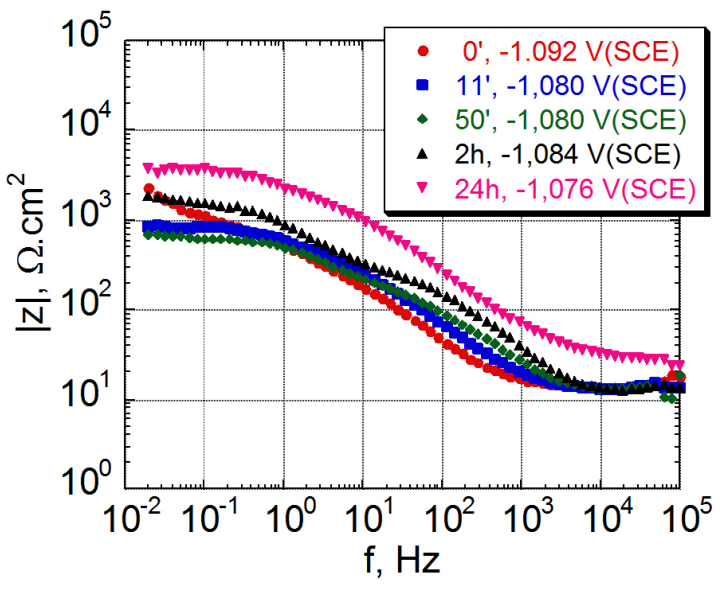

(a)

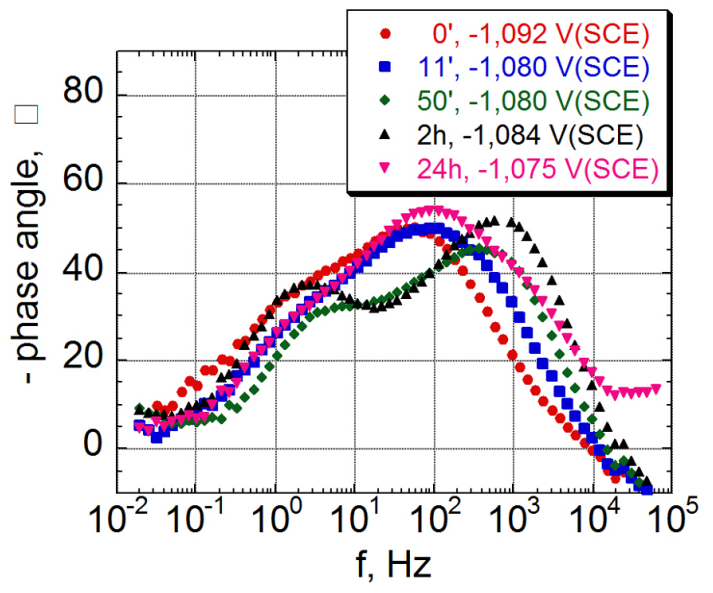

(b)

Figure 4. (a) Bode magnitude and (b) phase angle plots as a function of immersion time in aerated 0.3 mol. $\mathrm{L}^{-1} \mathrm{Na}_{2} \mathrm{SO}_{4}, \mathrm{pH} 10$, solution, for nitro-cobalt electrogalvanised steel coating - sample protected with treatment $B$. the immersion, which as already can represent a very unstable situation, the impedance at low frequency $(0.02 \mathrm{~Hz})$ clearly decreased almost an order the magnitude from the $11 \mathrm{~min}$ up to $2 \mathrm{~h}$ of immersion, but thenceforth it remained apparently without changes until the $24 \mathrm{~h}$. In principle, this evolution suggests the presence of an initially increasing electrochemical activity within the coating layer and at the zinc/coating interface, which attained an apparent equilibrium state as the exposure time elapsed since the impedance spectrum at the lower frequencies and after $24 \mathrm{~h}$ overlapped with the obtained at $2 \mathrm{~h}$. Such interpretation was confirmed by the angle phase evolution, Figure 5b, where the maximum value not only shifted towards higher frequencies but also decreased indicating the loss of part of the coating dielectric capacitance (i.e., its isolating effect). As well, the appearance of a well-defined third time constant in the impedance spectrum obtained after $24 \mathrm{~h}$ of exposure demonstrate that even though at the lower frequency the $|\mathrm{Z}|$ value at this time was equal than the obtained at $2 \mathrm{~h}$, the resistive and capacitive components contributing to such

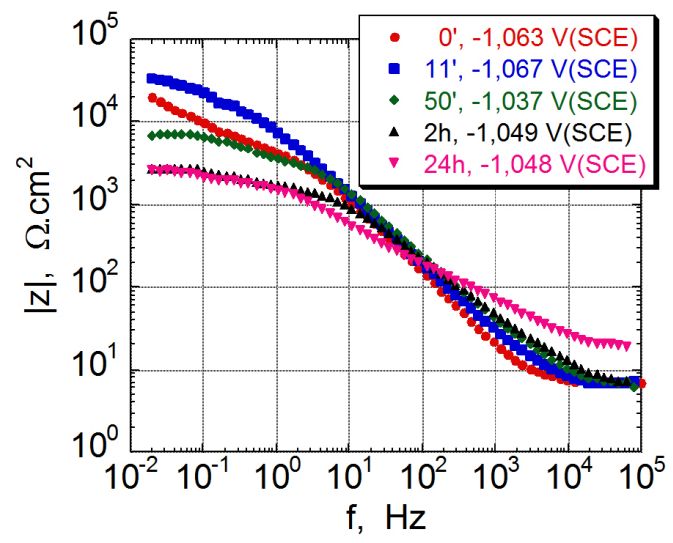

(a)

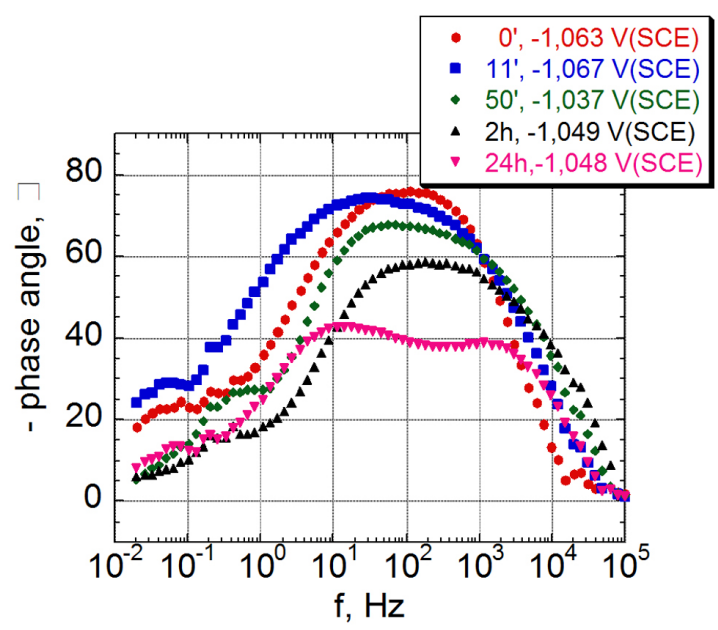

(b)

Figure 5. (a) Bode magnitude and (b) phase angle plots a function of immersion time in aerated 0.3 mol. $\mathrm{L}^{-1} \mathrm{Na}_{2} \mathrm{SO}_{4}, \mathrm{pH} 10$, solution, for phosphatized electrogalvanised steel coating - sample protected with treatment $\mathbf{C}$. 
value changed quali- and quantitatively. In this case, it was assumed that the corrosion resistance diminishing of the coated sample was compensated by the contribution of the barrier effect afforded by the corrosion products gathered within the coating defects.

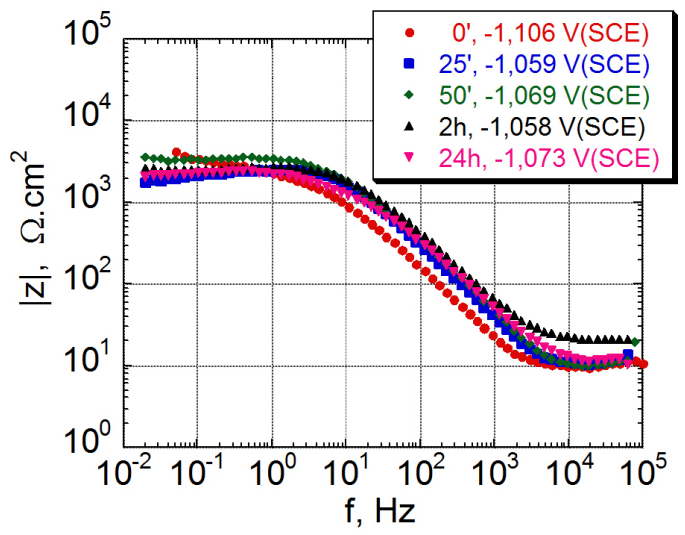

(a)
With regard to the sample D, Figure 6a, it can be seen that at low frequencies it exhibited slightly higher initial $|\mathrm{Z}|$ value $\left(\approx 4.10^{3} \Omega \mathrm{cm}^{2}\right)$ than those $\left(1.5-2.7 \Omega \mathrm{cm}^{2}\right)$ obtained at longer immersion times in the test solution. All these values were suggesting an electrochemically active interface. This type of behavior could be explained

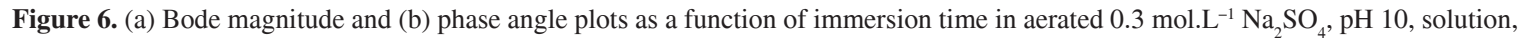
for $\mathrm{Cr}^{6+}$ chromated electrogalvanised steel sample - sample protected with treatment $\mathbf{D}$.

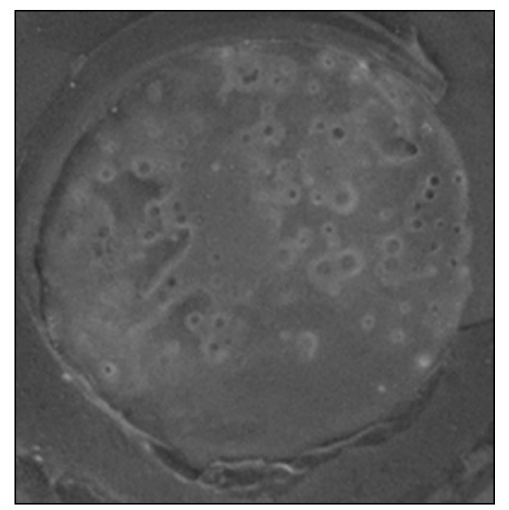

(a) sample protected with treatment $\mathbf{A}$

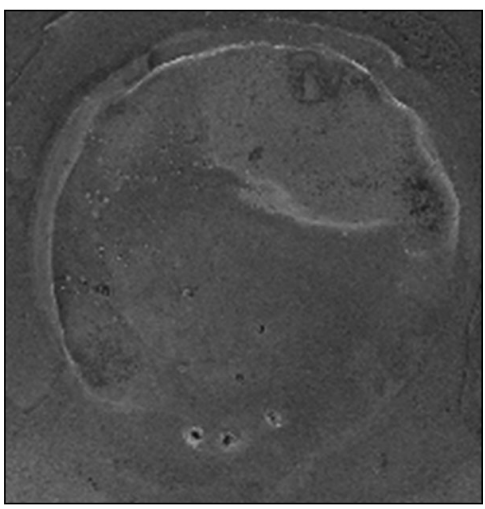

(c) sample protected with treatment $\mathbf{C}$

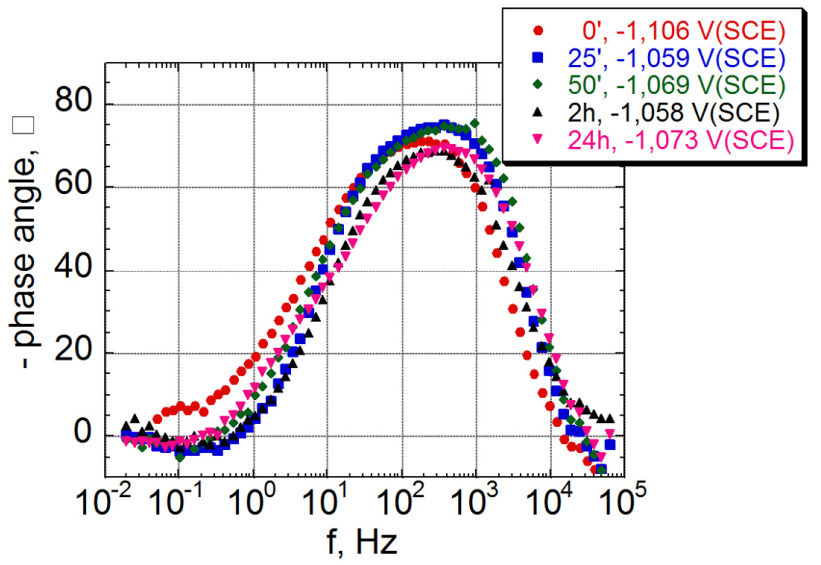

(b)

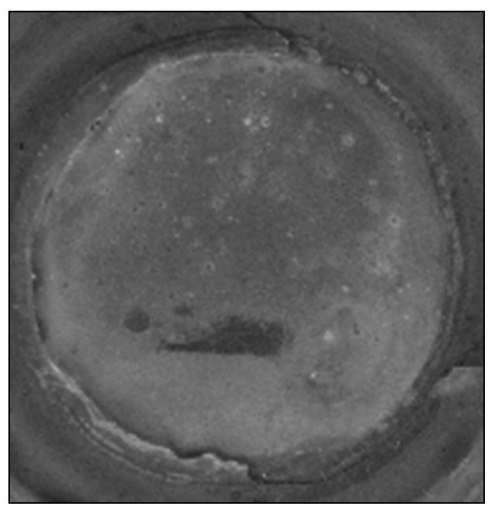

(b) sample protected with treatment $\mathbf{B}$

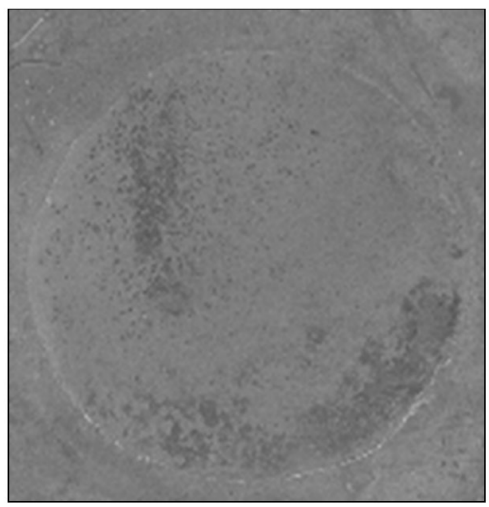

(d) sample protected with treatment $\mathbf{D}$

Figure 7. Visual aspect of the samples after $24 \mathrm{~h}$ immersed in aerated $0.3 \mathrm{~mol} . \mathrm{L}^{-1} \mathrm{Na}_{2} \mathrm{SO}_{4}$ solution, $\mathrm{pH} 10$, at room temperature. 
assuming that initially the loose corrosion products tended to become more compact, but as the time elapsed, part of them diffuse towards the electrolyte contributing to slightly diminish the coating resistive and capacitive properties. Despite this, changes underwent by the conversion layer had no significant effect on the corrosion behavior of the total coating probably due to the $\mathrm{Cr}^{+6}$ content and its selfhealing characteristics.

Figure $6 \mathrm{~b}$ illustrates that the time constant defined in the low frequency region just after immersion disappeared after $25 \mathrm{~min}$ and was replaced by an inductive loop; also that at medium frequencies a maximum phase angle of $75^{\circ}$ was defined. As a second time constant did not appear in the impedance spectrum it was assumed, and confirmed by the visual inspection, that during this short period did not take place a significant zinc corrosion process.

\section{Visual Inspection}

After $24 \mathrm{~h}$ of immersion in aerated $0.3 \mathrm{~mol} \mathrm{~L}^{-1} \mathrm{Na}_{2} \mathrm{SO}_{4}$ solution, $\mathrm{pH} 10$, the visual aspect of the electrogalvanised and treated A, B, C or $\mathbf{D}$ samples is depicted in Figure 7. In it can be seen that the surface of the sample $\mathbf{A}$ showed more white (zinc) and reddish (steel) corrosion products than the sample $\mathbf{C}$, while in the case of the samples $\mathbf{B}$ and $\mathbf{C}$ only white corrosion products could be seen at naked eye. Probably due to the self-healing effect provided by the free- $\mathrm{Cr}^{6+}$ ions able to diffuse within the conversion layer structure, the sample $\mathbf{D}$ was the less attacked.

\section{Conclusions}

The development of the present experimental study for $24 \mathrm{~h}$ of immersion in naturally aerated $0.3 \mathrm{~mol} \mathrm{~L}-1 \mathrm{Na}_{2} \mathrm{SO}_{4}$ solution, $\mathrm{pH} 10$, allows the following main conclusions to be drawn:

- The electrochemical response given by the same samples subjected to anodic and cathodic polarizations allowed to infer that: 1) the corrosion current densities

\section{References}

1. Zaki N. Chromate conversion coatings for zinc. Metal Finishing. 1988; 86(2):75-76.

2. Hagans PL and Hass CM. ASM Handbook Surface Engineering. 1994. p. 405.

3. Almeida E, Diamantino TC, Figueiredo MO and Sá C. Oxidising alternative species to chromium VI in zinc galvanized steel surface treatment. Part 1- a morphology and chemical study. Surface Coating Technology. 1998; 106(1):817. http://dx.doi.org/10.1016/S0257-8972(98)00464-2

4. Almeida E, Diamantino TC, Figueiredo MO and Sá C. Oxidising alternative species to chromium VI in zinc galvanized steel surface treatment. Part 2- an electrochemical study. Surface Coating Technology. 1998; 105(1-2):97-101. http://dx.doi.org/10.1016/S0257-8972(98)00476-9

5. Tomachuk CR, Elsner CI and Di Sarli AR. Morphology and corrosion resistance of $\mathrm{Cr}$ (III)-based conversion treatments for electrogalvanized steel. Journal Coating Technology estimated from the Tafel slopes extrapolation were rather similar; 2) the polarization level for the oxygen reduction reaction as a function of the treatment composition was ranked in the order: $\mathrm{A} \equiv \mathrm{C} \approx \mathrm{D}$ $>\mathrm{B}$; and 3) regardless the chemical composition of the conversion layer, the corrosion rate was under cathodic control (oxygen diffusion);

- The open-circuit potential evolution as a function of the immersion time could be used to evaluate the samples' corrosion behavior at least from a thermodynamic point of view;

- The EIS data showed that within the two first hours of immersion the evolution of the total impedance and phase angle values in the four coated samples was clearly differentiated and indicative of significant electrochemical activity. However, after 24 hours of immersion mainly the impedance values were rather similar. This was explained assuming that once formed the layer of zinc corrosion products, which blocked the conversion coating defects, the zinc corrosion process in the localized areas underneath that layer should not be very different. From the experimental data, a ranking of corrosion protective properties afforded by the different conversion treatments would be as follows: $\mathrm{D} \approx \mathrm{C}>\mathrm{B}>\mathrm{A}$;

- Visual inspections at naked eye of the tested samples allowed concluding that, the D samples did not show corrosion but the other presented different forms of attack. White and reddish corrosion products (samples A), only white (B and C samples).

\section{Acknowledgements}

This research was financed by Comisión de Investigaciones Científicas de la Provincia de Buenos Aires (CICPBA), Consejo Nacional de Investigaciones Científicas y Técnicas (CONICET) and Universidad Nacional de La Plata (UNLP) of Argentina.

Research. 2010; 7:493-502. http://dx.doi.org/10.1007/s11998009-9213-1

6. Tomachuk CR, Elsner CI, Di Sarli A and Ferraz OB. Corrosion resistance of $\mathrm{Cr}$ (III) conversion treatments applied on electrogalvanised steel and subjected to chloride containing media. Materials Chemistry and Physics. 2010; 119(1-2):1929. http://dx.doi.org/10.1016/j.matchemphys.2009.07.041

7. Korobov VI, Loshkarev YM and Kozhura OV. Cathodic treatment of galvanic zinc coatings in solutions of molybdates. Russian Journal of Electrochemistry. 1998; 34(11):1154-1157.

8. Deck PD and Reichgott DM. Characterization of chromiumfree no-rinse prepaint coating on aluminum and galvanized steel. Metal Finishing. 1992; 9(90:29-35.

9. Hinton BRW. Corrosion prevent and chromates, the end of an era? Metal Finishing. 1991; 89:55-61.

10. Barbucci A, Delucchi M and Cerisola G. Study of chromatefree pretreatments and primers for the protection of galvanized steel sheets. Progress Organic Coating. 1998; 33(2):131-138. http://dx.doi.org/10.1016/S0300-9440(98)00046-0 
11. Wilcox GD and Wharton JA. A review of chromate-free passivation treatments for zinc and zinc alloys. Trans IMF. 1997; 75(4):B140-146.

12. Tomachuk CR and Di Sarli AR. Study of coating applied on zinc surface. British Journal of Engineering and Technology. 2012; 1(1):78-96.

13. González S, Gil MA, Hernández JO, Fox V and Souto RM. Resistance to corrosion of galvanized steel covered with an epoxy-polyamide primer coating. Progress Organic Coating. 2001; 41(1-3):167-170. http://dx.doi.org/10.1016/S03009440(01)00139-4

14. Montemor MF, Simões AM and Ferreira MGS. Composition and corrosion behaviour of galvanised steel treated with rare-earth salts: the effect of the cation. Progress Organic Coating. 2002; 44(2):111-120. http://dx.doi.org/10.1016/ S0300-9440(01)00250-8

15. American Society for Testing and Materials - ASTM. B11711: Standard practice for operating salt spray (fog) apparatus. ASTM; 2011. 12 p.

16. Deutsches Institut für Normung - DIN. 50018 (1997-6): Sulfur dioxide corrosion testing in a saturated atmosphere. DIN; 1997. 3 p.

17. Deutsches Institut für Normung - DIN. 50017 (1982-10): Atmospheres and their technical application condensation water test atmospheres. DIN; 1982. 5 p.

18. MacDonald JR. Impedance Spectroscopy Emphasizing Solid State Materials. New York: J. Wiley \& Sons; 1987.

19. Mansfeld F. Models for the impedance behavior of protective coatings and cases of localized corrosion. Electrochimica Acta. 1993; 38(14):1891-1897. http://dx.doi.org/10.1016/00134686(93)80311-M
20. Carbonini P, Monetta T, Nicodemo L, Mastronardi P, Scatteia B and Bellucci F. Electrochemical characterization of multilayer organic coatings. Progress Organic Coating. 1996; 29(1-4):1320. http://dx.doi.org/10.1016/S0300-9440(96)00628-5

21. De Rosa L, Monetta T, Mitton DB and Bellucci F. Monitoring degradation of single and multilayer organic coatings. I. Absorption and transport of water: theoretical analysis and methods. Journal Electrochemistry Society. 1998; 145(11):3830-3838. http://dx.doi.org/10.1149/1.1838881

22. Hazan J, Coddet C and Keddam M. Study of chromate coatings on zinc by means of DC, AC and gravimetric methods in alkaline electrolyte-correlation to humid-storage test and CrVI content of the conversion film. Corrosion Science. 1990; 31:313-318. http://dx.doi.org/10.1016/0010-938X(90)90125-O

23. D'Alkaine CV and Boucherit MN. Potentiostatic Growth of $\mathrm{ZnO}$ on $\mathrm{Zn}$ : Application of an Ohmic Model. Journal of The Electrochemical Society. 1997; 144:3331-3336.

24. Boshkov N, Petrov K and Raichevsky G. Corrosion behavior and protective ability of multilayer galvanic coatings of $\mathrm{Zn}$ and Zn-Mn alloys in sulfate containing medium. Surface Coating Technology. 2006; 2009(20-21):5995-6001. http://dx.doi. org/10.1016/j.surfcoat.2005.10.002

25. Mansfeld F. Use of electrochemical impedance spectroscopy for the study of corrosion protection by polymer coatings. Journal Applied Electrochemistry. 1995; 25:187-202. http:// dx.doi.org/10.1007/BF00262955 